\title{
An Experimental Study On Evaporation Heat Transfer And Pressure Drop Of R-1234ze(E) In A Disk Type Plate Heat Exchanger
}

\author{
DongChan Lee', Dongwoo Kim¹, Junyub Lim¹, Wonseok Yang', Yongchan Kim² \\ ${ }^{1}$ Graduate Ischool of Mechanical Engineering, Korea University \\ Anam-ro 145, Seongbuk-gu, Seoul, Republic of Korea \\ 1dc1120@korea.ac.kr; redadol@korea.ac.kr; diglim@daum.net; yws1561@naver.com \\ ${ }^{2}$ Department of Mechanical Engineering, Korea University \\ Anam-ro 145, Seongbuk-gu, Seoul, Republic of Korea \\ yongckim@korea.ac.kr
}

\section{Extended Abstract}

In order to reduce greenhouse gas emission, conventional refrigerants with high global warming potential need to be replaced according to international agreements such as Kyoto Protocol and F-gas regulation [1-2]. In accordance with this global trend, numerous researches on the alternative refrigerants have been conducted. Hydrofluoroolefin (HFO) refrigerants such as R-1234ze(E) and R-1234yf have been nominated as powerful candidates for the substitute refrigerants with low GWP because of their short atmospheric life time due to double bond between carbons [3]. Papers that analyzed properties and basic heat transfer and flow characteristics of HFO refrigerants have been published extensively [4-5]. However, studies of R-1234ze(E) in various kinds of heat exchangers are still limited, which should be conducted for practical applications of the alternative refrigerants [6]. Therefore, evaporation heat transfer and pressure drop characteristics of R-1234ze(E) in a disk type plate heat exchanger are investigated in this study. A plate heat exchanger has been widely used as a heat exchanger in a heat pump, power cycle and food treatment industry due to its compactness, high cost effectiveness and heat exchange efficiency [7]. The disk type plate heat exchanger is one kind of the plate heat exchanger and it can sustain higher operating pressure than brazing type plate heat exchanger. In this study, the system that can measure the heat transfer and the pressure drop in the disk type plate heat exchanger is constructed using the refrigerant pump for circulation of the refrigerant, the preheater for the vapor quality control and the cooling chiller for the operating temperature control. Four parameters were set as variables for operating conditions; temperature ranged from 5 to $15^{\circ} \mathrm{C}$, heat flux ranged from $\mathrm{kW} \mathrm{m}^{-2}$, mass flux ranged from 10 to $20 \mathrm{~kg} \mathrm{~s}^{-1} \mathrm{~m}^{-2}$ and vapor quality ranged from 0.1 to 0.9 . The frictional pressure drop depended highly on the vapor quality while the heat transfer coefficient showed trivial dependence on the vapor quality. The increase in the mass flux results in enlarged pressure drop and heat transfer coefficient due to intensified turbulence of the refrigerant. The heat transfer coefficient increased but the slope of the graph decreased with increasing heat flux. Opposite to the trend of the heat transfer coefficient, the pressure drop remained nearly constant with respect to the heat flux. The result and the experimental data of this study could be utilized for designing or estimating capacity of an evaporator with R-1234ze(E) and for numerical study on the system with R-1234ze(E).

\section{References}

[1] Kyoto protocol to the United Nations framework convention on climate change, UNFCCC, 1992.

[2] Directive 2006/40/EC Of The European Parliament And Of The Council of 17 May 2006 relating to emissions from air-conditioning systems in motor vehicles and amending Council Directive 70/156/EEC, Official Journal of the European Union, 2006.

[3] T. J. Wallington, M. P. Sulbaek, O. J. Nielsen, "Atmospheric chemistry of short-chain haloolefins: Photochemical ozone creation potentials (POCPs), global warming potentials (GWPs), and ozone depletion potentials (ODPs)," Chemosphere, vol. 129, pp. 135-141, 2015.

[4] R. Nagata, C. Kondou, S. Koyama, "Comparative assessment of condensation and pool boiling heat transfer on horizontal plain single tubes for R1234ze(E), R1234ze(Z), and R1233zd(E)," Int. J. Refrig., vol. 63, pp. 157-170, 2016. 
[5] S. Grauso, R. Mastrullo, A. W. Mauro, J. R. Thome, G. P. Vanoli, "Flow pattern map, heat transfer and pressure drops during evaporation of R-1234ze(E) and R134a in a horizontal, circular smooth tube: Experiments and assessment of predictive methods," Int. J. Refrig., vol. 36, pp. 478-491, 2013.

[6] D. H. Kim, H. W. Byun, S. H. Yoon, C. H. Song, K. H. Lee, O. J. Kim, "The latest review of low GWP(<100) HFO refrigerants and studies on the pool boiling heat transfer," Int. J. Air-Cond. Refrig., vol. 24, no. 4, p. 1630009, 2016.

[7] Y. Y. Hsieh, T. F. Lin, "Saturated flow boiling heat transfer and pressure drop of refrigerant R-410A in a vertical plate heat exchanger," Int. J. Heat Mass Transf., vol. 45, pp. 1033-1044, 2002. 